\title{
Egos at the Table, a Study of Meeting Behaviors
}

\author{
Terry Oroszi \\ Boonshoft School of Medicine, Wright State University, Fairborn, OH, USA \\ Email: terry.oroszi@wright.edu
}

How to cite this paper: Oroszi, T. (2020) Egos at the Table, a Study of Meeting Behaviors. Psychology, 11, 636-645. https://doi.org/10.4236/psych.2020.114043

Received: March 26, 2020

Accepted: April 24, 2020

Published: April 27, 2020

Copyright $(2020$ by author(s) and Scientific Research Publishing Inc. This work is licensed under the Creative Commons Attribution International License (CC BY 4.0).

http://creativecommons.org/licenses/by/4.0/

\begin{abstract}
When organization members gather in groups of two or more to communicate, problem-solve, or make decisions, it is done so to improve information flow and disseminate information. Organizational meetings are often seen by employees as an unnecessary evil, a waste of time that distracts them from achieving the goals (Robinson, 2019). This appears to be a contradiction. To determine the cause of ineffective meetings the author performed a deep dive into the current literature. Meeting attendees often impede effective meetings with verbal and nonverbal behaviors. Rogelberg, Allen, Shanock, Scott, \& Shuffler (2010) asserted that non-effective meetings are inefficient, diminish morale and job satisfaction. Hartnett (2011) demonstrated that the facilitator has the duty to accomplish the objectives of the meeting, ensure that the purpose is clear, maintain order and establish an open process of communication. However, these authors found that group or committee members' goals may be inconsistent with the facilitator's agenda. Often in meetings there is an unspoken power struggle. Documented issues that impair or interfere with the process or outcome of effective meetings include group members wanting a voice, having their accomplishments heard, or ideas shared. An additional challenge outlined in the literature that contributes to meeting ineffectiveness is a feeling of powerlessness. Some have suggested (Atkins, 2002) that although full of poignant ideas, meeting participants who feel powerless, may not have the capacity to express thoughts or concerns. The following paper will identify how meeting attendees affect the meeting, including the verbal and nonverbal cues that interfere with effective meeting outcomes and provide alternative management strategies to facilitate effective meetings.
\end{abstract}

\section{Keywords}

Meetings, Organization, Workplace, Facilitation, Verbal, Nonverbal, Power

\section{Purpose of Meetings}

There is extensive research available on effective meeting styles, but there is a 
paucity of data on the impact the attending members have on effectiveness. Verbal and nonverbal cues that illustrate the members' power, or the lack of power, are examined. Furthermore, the role demographics, like rank and gender of the group members, in relation to effective meeting outcomes, are examined to determine if there exists a potential debilitating effect on the group process.

Organizational meetings can be a dynamic instrument used to initiate conversations, disseminate information, or make decisions. It is well known that not all meetings are effective. Many believe meetings to be a waste of time, taking employees away from more important matters (Allen, Lehmann-Willenbrock, \& Rogelberg, 2018; Stray, 2018; Yoerger, Jones, Allen, \& Crowe, 2017; Mroz, Allen, Verhoeven, \& Shuffler, 2018). In a normal workday, as many as 55 million meetings happen every day. Employees spend on average six hours per week sitting in meetings (Lehmann-Willenbrock, Rogelberg, Allen, \& Kello, 2018). Depending upon the organization's culture, the costs of meetings, such as collective salaries of the attendees, and time, are incentives to have productive meetings (Leach, Rogelberg, Warr, \& Burnfield, 2009). Attending workplace meetings can cost members up to thirty percent of their workweek. According to Carlozzi (1999), one-half of that time is ineffective.

A significant amount of time is dedicated to organizational meetings, and while some meetings are productive, others are seen as "time wasters" (Sisco, 1993; Mankins \& Garton, 2017) and damage morale (Malouff, Calic, McGrory, Murrell, \& Schutte, 2012). Communication and decision-making are two functions for organizational meetings that lead to the feelings of productivity and improved job satisfaction.

\section{Barriers to Successful Meetings}

Members of an organizational meeting commonly use verbal and nonverbal interactions to achieve dominance in a meeting. The struggle for power negatively impacts the meeting and the ability to make group decisions. A group's output style and effectiveness were seen to have a link according to Cooke \& Szumal (1994), with constructive behavior positively related to solution quality and acceptance, and passive behavior negatively linked. Aggressive behavior was unrelated to quality, but was found to be negatively related to acceptance of the proposed decision. The rationale of this paper was to explore power behaviors seen in meetings and to identify the relationship of this behavior by rank, gender, and/or ethnicity.

In 2016, Lehmann-Willenbrock, Beckand Kauffeld, videotaped and analyzed fifty-nine organizational meetings and were able to classify five member types based on the behavior they witnessed: the solution seeker, the problem analyst, the procedural facilitator, the complainer, and the indifferent. By breaking down the attendees into these five categories it is easy to see why a problem exists. What is does not do is speak to how effectively the members communicate with each other. 


\section{Power}

Power is the ability to exert influence and the proficiency of a leader to exercise its will on those which disagree (Max, 1947). Power is the capacity to control what happens (Berko, Rosenfeld, \& Samovar, 1997). Power is the ability to influence the attitudes and actions of others (DeVito, 2010). The variable of power, as a stand-alone construct, can be used as a positive or negative behavioral shaping technique in group meetings. Power can be easily recognized at a meeting, and may be displayed as rank, title, or may be hidden and unspoken. The desire for power can make organizational meetings a battlefield and decrease the meeting's effectiveness.

Leaders demonstrate power or powerlessness by verbal and nonverbal behavior (Atkins, 2002). Further research by Atkins (2002) identified individuals who use powerful language will be viewed more positively than those who use powerless language. Meeting attendees determine the relative distribution of power among meeting members by observing both verbal and nonverbal indicators (Rothwell, 2010). A mixed message is when the verbal and nonverbal cues contradict each other; typically the nonverbal is more powerful and most accurate (Umiker, 1990).

Power is fluid and is exchanged between members. A person alone cannot have power, others are needed to confirm and give the power to the individual. Power is often negotiated and shared by all members of a meeting engaged in interaction. Diamond (1996) stated that denying others the status of leader, or not acknowledging the colleagues' leadership role can be a tactical power strategy. In some organizations institutionalized rank, such as doctors and professors, has been automatically equated to power. The inferior ranked participant may have skills to prevent the superior from the power role (Davis, 1988; Lakoff, 1989). Examples of the inferior preventing the superior from taking the power role include the inferior dressing more professionally, superior speaking skills, working more efficiently with better results, and being seen as an informal leader by other members.

The power one possesses at a meeting is based on the perceptions of those attending the meeting. Methods people use to exude the perception of power are quite diverse. One non-verbal method of obtaining or giving the illusion of power in meetings is professional attire. Members signal their nonverbal power through clothing and conservative (Lewis, 1989; Rothwell, 2010). An example of this was offered by Mercer, MacKay-Lyons, Conway, Flynn, \& Mercer (2008), stating a preference for a more formal attire by students and faculty at some institutions. People make perceptions about the attire of a person, regardless if it is right or wrong (Sternberg, 2003).

\section{Nonverbal}

Nonverbal communication, such as body language and facial expressions, can be just as important as verbal communications. When done simultaneously with 
verbal interactions, non-verbal communication can aid in the understanding of the interactions as it unfolds (Gorse \& Emmitt, 2007). Verbal communication is enhanced when non-verbal, and sign language cues are implemented, such as frowns, smiles, winks, and nods. Other recognized facial expressions are surprise, fear, anger, disgust, happiness, and sadness (Umiker, 1990).

It is not uncommon to have a power competition within the group, outside of the leader or facilitator. Violence or coercion, although ill-advised, is effective techniques to achieve power; however, threats of violence, or coercive behaviors do not change the point of view of the target. Skills utilizing verbal and nonverbal cues can be more efficient uses if persuasion is the goal (Dahl, 1957). Rank alone is not sufficient to determine power; one must possess both rank and power to be successful. There are actions labeled as dominant, powerful behaviors such as introducing a topic, fighting to get the floor, or interrupting others (Davis, 1988; Zimmermann \& West, 1996).

Effective verbal and nonverbal communication skills are paramount when serving as a leader or as the perceived leader (Atkins, 2002). Nonverbal communication in a meeting, such as body language, posture, eye contact, and facial expressions can send power signals to other attendees as easily as verbal cues. A leader who exudes power at a meeting can control nonverbal cues and emotions (e.g. raising an eyebrow, glaring, sighs), using them to their advantage. Stationary sitting, another powerful nonverbal cue, will illustrate power. Touching, although not often seen at meetings, can be very powerful when wanting to get the attention of another meeting attendee. A light touch on the arm or hand sends a message of confidence, praise, and security. When the meeting member is addressed by name the leader's power and influence is increased (Kippenbrock, 1992).

Neuman \& Baron (1998) proposed that non-verbal interactions can be examples of workplace aggression, in a physical, passive and indirect method. Members' opinions on meetings will affect their attendance, behavior, and the ability of meetings to complete their tasks (Leach et al., 2009). According to Barsade (2002), emotions in a meeting can be contagious, unpleasant emotions are more contagious than happier ones.

In some work cultures, as well as countries and regions like the Gulf Arab region, attendance time is flexible (Kemp \& Williams, 2013); however, in most organizations in the United States the start time of a meeting is important. Showing up at a meeting early, arriving before the other meeting members, and greeting them as they enter, is a simple method of demonstrating power. If one is not the official leader of the meeting, but aspires to be the leader, placement is important. Sitting to the left of the official leader is the next place of power (Kippenbrock, 1992).

Nonverbal cues include silent meeting members. Not speaking at a meeting can be due to several factors including shyness. Silence can be gender-related, as Umiker (1990) pointed out, women are known to speak less often in meetings. Silence in a meeting can also be a form of passive-aggression. Silence as a beha- 
vior tool can be exhibited in a way that does not offend the other meeting members yet can still reflect hostility (McIlduff \& Coghlan, 2000).

\section{Verbal Cues}

When witnessing members' interactions in meetings, it is easy to identify verbal cues used to acquire power or to denote power. The use of verbal clues in a meeting is an efficacious tool to denote power or powerless. Hijacking is a term for common verbal behaviors related to speaking in meetings: interruption, recovery, monologuing, swerving, and crying. These behaviors redirect attention from the group and target the focus on the person.

Interruption is when a speaker has his or her works or thoughts disturbed. It is powerful because it allows the interrupted speaker to gain control of the conversation and have their thoughts heard instead (Stratford, 1998). How members handle being interrupted, talking louder or not talking can be just as disruptive to the meeting's success. Interrupting a conversation occurs more often in men than women and is examined further in the gender section.

Introducing new topics of conversation and the use of open-ended questions are effective verbal tools (DeVito, 2010). Raising the voice is a way to generate power in meetings, making it a valuable method to take control of a meeting (Umiker, 1990). When the facilitator of a meeting initiates open-ended questions, a collaborative tone is established and encourages further communication in the meeting.

Monologues can be used as a power play and describe the behavior when a member answers a question, but elaborates on the topic longer than necessary. Occasionally this behavior is seen, not just excessively talking, but changing the subject to something that is of interest to them in the process. Sometimes this is done even during a vote and can stall or prolong the voting process.

If an individual works in a mission-based organization or health care environments crying in the workplace may appear more human and caring. People may respond favorably to such an event. However, crying in a meeting is not common. Wasson (2000) pointed out, the process of reaching consensus in a meeting can be quite emotional and may include conflict, crying, posturing and yelling. This behavior removes power from the individual and disrupts the meeting. Exhibiting such emotions may cause the member to appear weak and powerless.

Another verbal distraction is the practice of having private (sidebar) conversations when others are speaking. The individual conversations are frequently off-topic, may serve as an interruption, and interfere with the flow of the meeting. Yankelovich et al. (2005) assert that private communications can help people get instant feedback and get clarification without being overly disruptive, it should not always be considered bad conduct.

\section{Impact of Demographics in Meetings}

There are particular demographics that may influence the power at meetings. 
Rank and gender are among them. Van Bunderen, Greer, and Van Knippenberg (2018) performed an analysis of study of 243 organizational meetings and witnessed conflict and power struggles in ranked (but not equal) teams. As expected, team performance during those meetings was negatively affected.

In some countries, rank and class are crucial. Revering hierarchy in China and Russia, as well as India, would be quite common whereas in Germany and the United States it is less important. Exceptions to this in the United States can be seen in the US military and politics, like in the US Senate. Rank can be the academic or organizational title of the individual, time in the institution, education, or relationship to those in greater authority positions. There are several other factors that contribute on smaller scales, such as marital status and age, but are beyond the focus of this paper. In most cases, rank is a fixed variable, and the power it affords one in a meeting may depend on the other members at the table (Diamond, 1996). For example, a chairman of a department meeting will be perceived as the one with the most power, but in a meeting with deans a chairman may be just another participant.

Understanding the consequences of power communication with respect to gender issues can impact their interaction with others (Atkins, 2002). When men talk it sounds more like a lecture, demanding, and authoritative. They are also known to inform and correct. Women, on the other hand, tend to ask questions, speak to encourage others and offer support (Tannen, 1991). When men and women communicate, it can be seen as a conversation between cultures in which two different languages are spoken (Kramarae, 1981).

Some complex factors need to be understood when analyzing gender in the workplace (Mullany, 2004). Zimmermann and West (1996) describe the tendency for males to interrupt a conversation. Muted group theory is the term assigned to the non-dominant groups in society, those that have less of a voice, like women, ethnic minorities, the sick, disabled and poor. Because women collectively have a lower status than men their voice can be considered less valuable and is often ignored (Kramarae, 1981). Although women's status has improved in most societies over the last century, women still lack access to power and leadership when compared to men (Carli \& Eagly, 2001).

\section{Success}

Effective meetings allow members to share ideas, establish connections, and make decisions. Both formal and informal meetings can lead to successful completion of tasks. Previous research by Rogelberg, Allen, Shanock, Scott, \& Shuffler (2010) included two studies that determined this correlation. The first study used a sample size of $201,60 \%$ female. The mean age of the participants was 36.5 years, with a mean tenure of 7.8 years. Rogelberg et al. (2010) first measured the five facets of job satisfaction and a 6-item scale for meeting satisfaction. Meeting satisfaction utilized six adjectives: stimulating, satisfying, boring, unpleasant, enjoyable and annoying. Study two was an internet study with a sample size of 
785. The findings revealed a correlation between job satisfaction and productive meetings $(p<0.05)$.

Improving effectiveness of meetings can aid in overall work performance and job satisfaction (Gorse \& Emmitt, 2007). Having rules, structure and purpose in the meeting can increase the chances of success. To ensure this, all members must understand the said rules and purpose. Structure can be gained by simply having an agenda, and following it, without outside disturbances (Lynch \& Crawford, 2017; Maurer, 2019; Robinson, 2019). Maurer (2019) further asserts that the length of the meeting matters, they should be as short as possible.

Gorse and Emmitt (2007) theorized that an increase in group professionalism will enhance a more group task-driven style. They further assert behavior differs when the group members are well acquainted. As groups develop, they form relationships with other members and become less task oriented, and more socio-emotional driven. Temporary groups never reach this state of informality.

What makes a team successful at having productive meetings depends on the meeting members and its use of a facilitator (Pasmore \& Woodman, 2017). Maurer (2019) polled 144 leaders from all levels in an organization, asking them what makes an effective meeting. The top responses were: Two-way communication, transparent leadership, and those that were purposeful, covering issues important to them.

Frequently member to member interactions and displayed behavior have detrimental effects on the group's performance and ability to complete a task (Hackman \& Morris, 1974) and a facilitator can work to prevent the bad behavior. The facilitator should be aware of the impact the demographics have on the success of the meeting. Some of the power exchange, with regard to rank, may be obvious to the facilitator and the meeting participants; however, when it relates to gender the signs may be more subtle and culture based.

In Hartnett's (2011) conceptual model, the purpose of the meeting facilitator is one of guided direction. The facilitator has an additional purpose, to empower and inspire the group members (Blanchard \& McBride, 2020). It is important to note the facilitator is not always the leader of the meeting; he or she may be someone separate from the group. Often nonmembers are acquired from the external environment to ensure that when acting as the facilitator the role is process, not content, driven. When guiding the group, there are two parallel processes operating simultaneously. The first is an assertive style while leading the members, and second, doing this in a positive tone. Both are essential for a successful outcome in meetings. When everyone at the table has an opportunity to express their opinion, regardless of rank or title, the organization or groups' collective power is increased (IBID).

\section{Conclusion}

The present descriptive study seeks to critically analyze meetings to improve their productivity by highlighting what works. In this review, the role of the 
group facilitator and the characteristics of a meeting are articulated while focusing on the dynamics of the group members and power exchange within the group.

Accomplishing a productive organizational meeting is a multifaceted process that requires pensive thought and purposeful behaviors. The battle for dominance in the group is evident with verbal and nonverbal cues. Power struggles interfere with the meeting agenda and the facilitator's role as a gatekeeper.

The ability of the facilitator to use the time effectively, stay task-driven, and parry the members fighting for power can only be realized if they know those cues. The facilitator must also be able to give a voice to those that feel powerless. Identifying the cues is an important step to productive decision making in organizational meetings.

\section{Conflicts of Interest}

The author declares no conflicts of interest regarding the publication of this paper.

\section{References}

Allen, J. A., Lehmann-Willenbrock, N., \& Rogelberg, S. G. (2018). Let's Get This Meeting Started: Meeting Lateness and Actual Meeting Outcomes. Journal of Organizational Behavior, 39, 1008-1021. https://doi.org/10.1002/job.22176

Atkins, C. P. (2002). Power Communication: Making an Educated Choice. Clinical Supervisor, 21, 207-232. https://doi.org/10.1300/J001v21n02_13

Barsade, S. G. (2002). The Ripple Effect: Emotional Contagion and Its Influence on Group Behavior. Administrative Science Quarterly, 47, 644-675. https://doi.org/10.2307/3094912

Berko, R. M., Rosenfeld, L. B., \& Samovar, L. A. (1997). Connecting: A Culture-Sensitive Approach to Interpersonal Communication Competency. Fort Worth, TX: Harcourt Brace College Publishers.

Blanchard, A. L., \& McBride, A. (2020). Putting the "Group” in Group Meetings: Entitativity in Face-to-Face and Online Meetings. In Managing Meetings in Organizations (Research on Managing Groups and Teams, Vol. 20) (pp. 71-92). Bingley: Emerald Publishing Limited. https://doi.org/10.1108/S1534-085620200000020004

Carli, L. L., \& Eagly, A. H. (2001). Gender, Hierarchy, and Leadership: An Introduction. Journal of Social Issues, 57, 629-636. https://doi.org/10.1111/0022-4537.00232

Carlozzi, C. (1999). Make Your Meetings Count. Journal of Accountancy, 187, 53-56.

Cooke, R. A., \& Szumal, J. L. (1994). The Impact of Group Interaction Styles on Problem-Solving Effectiveness. The Journal of Applied Behavioral Science, 30, 415-437. https://doi.org/10.1177/0021886394304005

Dahl, R. A. (1957). The Concept of Power. Behavioral Science, 2, 201-215. https://doi.org/10.1002/bs.3830020303

Davis, K. (1988). Power under the Microscope: Toward a Grounded Theory of Gender Relations in Medical Encounters. Dordrecht/Providence, RI: Foris Publications.

DeVito, J. A. (2010). Essentials of Human Communication (7th ed.). New York: Pearson Education.

Diamond, J. (1996). Status and Power in Verbal Interaction: A Study of Discourse in a 
Close-Knit Social Network. Amsterdam: John Benjamin's Publishing. https://doi.org/10.1075/pbns.40

Gorse, C. A., \& Emmitt, S. (2007). Communication Behaviour during Management and Design Team Meetings: A Comparison of Group Interaction. Construction Management \& Economics, 25, 1195-1211. https://doi.org/10.1080/01446190701567413

Hackman, J. R., \& Morris, C. G. (1974). Group Tasks, Group Interaction Process, and Group Performance Effectiveness: A Review and Proposed Integration. Fort Belvoir, VA: Defense Technical Information Center. https://doi.org/10.1016/S0065-2601(08)60248-8

Hartnett, T. (2011). Consensus-Oriented Decision-Making: The CODM Model for Facilitating Groups to Widespread Agreement. Gabriola: New Society Publishers.

Kemp, L. J., \& Williams, P. (2013). In Their Own Time and Space: Meeting Behavior in the Gulf Arab Workplace. International Journal of Cross-Cultural Management, 13, 215. https://doi.org/10.1177/1470595813485383

Kippenbrock, T. A. (1992). Power at Meetings: Strategies to Move People. Nursing Economics, 10, 282-286.

Kramarae, C. (1981). Women and Men Speaking: Frameworks for Analysis.

Lakoff, R. T. (1989). The Limits of Politeness: Therapeutic and Courtroom Discourse. Multilingua Journal of Cross-Cultural and Interlanguage Communication, 8, 101-130. https://doi.org/10.1515/mult.1989.8.2-3.101

Leach, D., Rogelberg, S., Warr, P., \& Burnfield, J. (2009). Perceived Meeting Effectiveness: The Role of Design Characteristics. Journal of Business \& Psychology, 24, 65-76. https://doi.org/10.1007/s10869-009-9092-6

Lehmann-Willenbrock, N., Beck, S. J., \& Kauffeld, S. (2016). Emergent Team Roles in Organizational Meetings: Identifying Communication Patterns via Cluster Analysis. Communication Studies, 67, 37-57. https://doi.org/10.1080/10510974.2015.1074087

Lehmann-Willenbrock, N., Rogelberg, S. G., Allen, J. A., \& Kello, J. E. (2018). The Critical Importance of Meetings to Leader and Organizational Success. Organizational Dynamics, 47, 32-36. https://doi.org/10.1016/j.orgdyn.2017.07.005

Lewis, D. (1989). The Secret Language of Success. New York: Carroll \& Graf.

Lynch, L., \& Crawford, K. (2017). EPIC Team Meetings.

Malouff, J. M., Calic, A., McGrory, C. M., Murrell, R. L., \& Schutte, N. S. (2012). Evidence for a Needs-Based Model of Organizational-Meeting Leadership. Current Psychology, 31, 35-48. https://doi.org/10.1007/s12144-012-9129-2

Mankins, M. C., \& Garton, E. (2017). Time, Talent, Energy: Overcome Organizational Drag and Unleash Your Teams Productive Power. Harvard Business Review Press.

Maurer, R. (2019). Are You Tired of Big All-Hands Meetings? The Journal for Quality and Participation, 41, 24-25.

Max, W. (1947). The Theory of Social and Economic Organization. Translated by Henderson, A.M. and Parsons, T., London: The Free Press of Glencoe Collier-Macmillan Limited.

McIlduff, E., \& Coghlan, D. (2000). Understanding and Contending with Passive-Aggressive Behavior in Teams and Organizations. Journal of Managerial Psychology, 15, 716-736. https://doi.org/10.1108/02683940010378072

Mercer, E., MacKay-Lyons, M., Conway, N., Flynn, J., \& Mercer, C. (2008). Perceptions of Outpatients Regarding the Attire of Physiotherapists. Physiotherapy Canada, 60, 349-357. https://doi.org/10.3138/physio.60.4.349

Mroz, J. E., Allen, J. A., Verhoeven, D. C., \& Shuffler, M. L. (2018). Do We Really Need 
Another Meeting? The Science of Workplace Meetings. Current Directions in Psychological Science, 27, 484-491. https://doi.org/10.1177/0963721418776307

Mullany, L. (2004). Gender, Politeness, and Institutional Power Roles: Humour as a Tactic to Gain Compliance in Workplace Business Meetings. Multilingua: Journal of Cross-Cultural and Interlanguage Communication, 23, 13-37. https://doi.org/10.1515/mult.2004.002

Neuman, J. H., \& Baron, R. A. (1998). Workplace Violence and Workplace Aggression: Evidence Concerning Specific Forms, Potential Causes, and Preferred Targets. Journal of Management, 24, 391-419. https://doi.org/10.1177/014920639802400305

Pasmore, W. A., \& Woodman, R. W. (2017). The Future of Research and Practice in Organizational Change and Development. In Research in Organizational Change and Development (Volume 25, pp. 1-32). Bingley: Emerald Publishing Limited. https://doi.org/10.1108/S0897-301620170000025001

Robinson, A. (2019). Meetings, Meetings: Make Them Work. In BSA VA Congress Proceedings 2019 (pp. 308-309). BSAVA Library. https://doi.org/10.22233/9781910443699.40.2

Rogelberg, S. G., Allen, J. A., Shanock, L., Scott, C., \& Shuffler, M. (2010). Employee Satisfaction with Meetings: A Contemporary Facet of Job Satisfaction. Human Resource Management, 49, 149-172. https://doi.org/10.1002/hrm.20339

Rothwell, J. D. (2010). In the Company of Others: An Introduction to Communication. Oxford: Oxford University Press.

Sisco, R. (1993). What to Teach Team Leaders. Training, 30, 62-67.

Sternberg, R. E. (2003). Attending to Teacher Attire. School Administrator, 60, 38.

Stratford, J. (1998). Women and Men in Conversation: A Consideration of Therapists' Interruptions in Therapeutic Discourse. Journal of Family Therapy, 20, 383-394. https://doi.org/10.1111/1467-6427.00094

Stray, V. (2018). Planned and Unplanned Meetings in Large-Scale Projects. In Proceedings of the 19th International Conference on Agile Software Development: Companion (pp. 1-5). https://doi.org/10.1145/3234152.3234178

Tannen, D. (1991). You Just Don't Understand: Women and Men in Conversation. London: Virago.

Umiker, W. (1990). How to Generate Power in Meetings. The Health Care Manager, 9, 33-38.

Van Bunderen, L., Greer, L. L., \& Van Knippenberg, D. (2018). When Interteam Conflict Spirals into Intrateam Power Struggles: The Pivotal Role of Team Power Structures. Academy of Management Journal, 61, 1100-1130. https://doi.org/10.5465/amj.2016.0182

Wasson, C. (2000). Caution and Consensus in American Business Meetings. Pragmatics, 10, 457-481. https://doi.org/10.1075/prag.10.4.03was

Yankelovich, N., McGinn, J., Wessler, M., Kaplan, J., Provino, J., \& Fox, H. (2005). Private Communications in Public Meetings. In CHI'05 Extended Abstracts on Human Factors in Computing Systems (pp. 1873-1876). https://doi.org/10.1145/1056808.1057044

Yoerger, M., Jones, J., Allen, J. A., \& Crowe, J. (2017). Meeting Madness: Counterproductive Meeting Behaviors and Personality Traits. International Journal of Management Practice, 10, 203. https://doi.org/10.1504/IJMP.2017.084938

Zimmermann, D. H., \& West, C. (1996). Sex Roles, Interruptions and Silences in Conversation. Amsterdam Studies in the Theory and History of Linguistic Science Series, 4, 211-236. https://doi.org/10.1075/cilt.125.12zim 